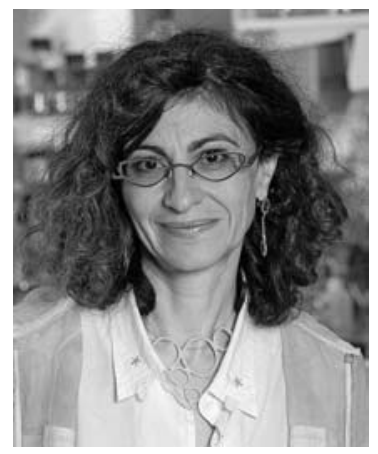

\title{
A Conversation with Geneviève Almouzni
}

\author{
INTERVIEWER: EytAN ZLOTORYNSKI
}

Senior Editor, Nature Reviews Molecular Cell Biology

Geneviève Almouzni is Director of the Chromatin Dynamics Group at the Curie Institute.

Eytan Zlotorynski: You're interested in chromatin structure and chromosome organization during the cell cycle and development, with a special interest in histone variants. Why histone variants and what is the significance of certain histone variants for chromosome organization?

Dr. Almouzni: Histone variants give variability to the basic particle, the nucleosome, by marking particular regions of the genome. The most striking example is the centromeric variant called CENP-A (centromere protein A) in mammals and CenH3 in other species, which marks the sites where the kinetochore forms, an important structure for segregating chromosomes.

Eytan Zlotorynski: What were your main findings about the roles of CENP-A and its interacting proteins in centromere formation during the cell cycle?

Dr. Almouzni: There's a very particular point during the cell cycle in late mitosis when CENP-A is deposited during the organization of the domain. That was surprising because we thought that deposition would happen after replication. In this case, there's a delay. There's a dilution of the centromeric variant and it's only deposited during late mitosis. The component responsible for regulating this time-dependent deposition is a chaperone protein called HJURP (Holliday junction recognition protein). We discovered HJURP at the same time as Don Cleveland by analyzing the complexes that are soluble prior to deposition.

Eytan Zlotorynski: Do you now know why deposition is delayed until the later phase?

Dr. Almouzni: HJURP is recruited when it's phosphorylated. You have to prevent early phosphorylation to restrict the time window when it attaches. That's important, but it's not enough. It also has to be active to enable the loading of CENP-A. That requires a particular property of HJURP that allows DNA binding.

There are also some posttranslational modifications on CENP-A itself that seem to participate in these dynamics. The whole area needs to be receptive for the centromeric variant to be brought in. There are other types of variants that can be modified. For example, modification by acetylation provides the potential to remodel the region and enable it to bind CENP-A.

Eytan Zlotorynski: At this stage, the entire chromosome is well packed. Does this open the chromosome specifically at the centromeres to be receptive?

Dr. Almouzni: Yes. This late stage of mitosis - early $\mathrm{G}_{1}$ is an important time when you reorganize the genome to enter into the next interphase and then $\mathrm{S}$ phase. It depends on the species, but in mammals it's during this mid-to-late period when the decision to replicate is made and presumably centromeres are marked for this late replication. It's also during this same period of reorganization where TADs (topologically associating domains) are observed.

Eytan Zlotorynski: HJURP, and possibly other histone chaperones, have roles in the DNA damage response. That suggests that they might have roles in cellular transformation or even tumorigenesis. Is anything known about the relation between histone variants or histone chaperones and cancer?

Dr. Almouzni: There's a particular mutation found in H3.3 that's associated with the pediatric glioblastoma. We're also trying to understand how there can be cross talk between the use of one variant or another by a particular chaperone. For example, HJURP is dedicated to CENP-A deposition. However, if there's an excess of CENP-A, another chaperone-Daxx (death-associated protein 6) takes over and deposits CENP-A at ectopic sites.

Eytan Zlotorynski: That creates a situation where you have several active kinetochores, which presumably leads to chromosomal missegregation?

Dr. Almouzni: Currently, our view is that an active kinetochore inhibits any other site from being active. If you disrupt the system, that unleashes the capacity to form a new kinetochore, enabling a particular cell to propagate, potentially giving them an advantage. 
Eytan Zlotorynski: But it's an advantage that could rise to cancer.

Dr. Almouzni: Yes, but the mechanism itself could help cells to evolve and adapt to the environment.

Eytan Zlotorynski: Do other regions of the chromosome beyond centromeres have such an intricate relationship between specific histone variants and their function?

Dr. Almouzni: One area of interest is the telomere. We've been exploring the function of another chaperone called ASF-1 (anti-silencing function 1) and found that when you downregulate ASF-1 you have mismanagement of the variant, and deposition in the telomere and the ALT (alternative lengthening of telomeres) pathway can be triggered. That's an alternative pathway connected to the DNA damage response and to cancer; a number of cancer cell types adopt the ALT pathway to survive. It enables some cancer cells to maintain the integrity of the telomeres by other means, even in the absence of telomerase. 


\section{$\$_{\text {CSH\& }}^{\infty}$ Cold Spring Harbor Symposia SYMPOSIA On Quantitative Biology}

\section{A Conversation with Geneviève Almouzni}

Cold Spring Harb Symp Quant Biol 2015 80: 297-298

Access the most recent version at doi:10.1101/sqb.2015.80.029926

\section{License}

Email Alerting Receive free email alerts when new articles cite this article - sign up in Service the box at the top right corner of the article or click here. 